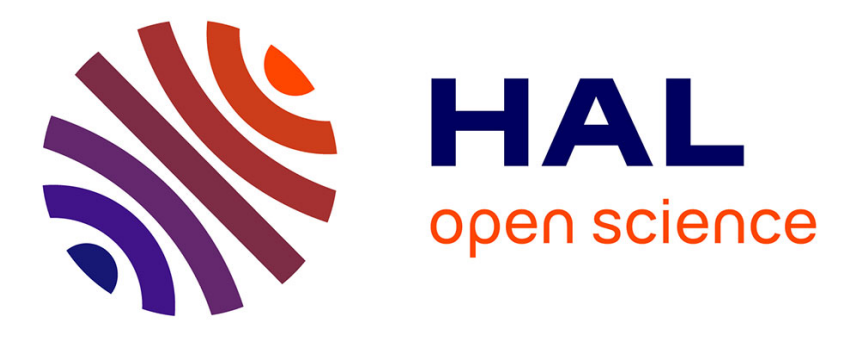

\title{
The Sm-Fe-V based 1:12 bulk magnets
}

\author{
A.M. M Schönhöbel, Rajasekhar Madugundo, A.M. M Gabay, J.M. M \\ Barandiarán, G.C. C Hadjipanayis
}

\section{To cite this version:}

A.M. M Schönhöbel, Rajasekhar Madugundo, A.M. M Gabay, J.M. M Barandiarán, G.C. C Hadjipanayis. The Sm-Fe-V based 1:12 bulk magnets. Journal of Alloys and Compounds, 2019, 791, pp.1122-1127. 10.1016/j.jallcom.2019.03.249 . hal-02264183

\section{HAL Id: hal-02264183 \\ https://hal.science/hal-02264183}

Submitted on 14 Sep 2019

HAL is a multi-disciplinary open access archive for the deposit and dissemination of scientific research documents, whether they are published or not. The documents may come from teaching and research institutions in France or abroad, or from public or private research centers.
L'archive ouverte pluridisciplinaire HAL, est destinée au dépôt et à la diffusion de documents scientifiques de niveau recherche, publiés ou non, émanant des établissements d'enseignement et de recherche français ou étrangers, des laboratoires publics ou privés. 


\title{
The Sm-Fe-V based 1:12 bulk magnets
}

A. M. Schönhöbel ${ }^{\mathrm{a}, \mathrm{b}}$, R. Madugundo ${ }^{\mathrm{a}}$, A. M. Gabay ${ }^{\mathrm{c}}$, J. M. Barandiarán ${ }^{\mathrm{a}, \mathrm{b}}$, G. C. Hadjipanayis ${ }^{\mathrm{c}}$

${ }^{a}$ BCMaterials, UPV/EHU Science Park, 48940 Leioa, Spain

${ }^{b}$ Department of Electricity \& Electronics, University Basque Country (UPV/EHU), 48940 Leioa, Spain

${ }^{c}$ Department of Physics \& Astronomy, University of Delaware, Newark, DE, 19716, USA

\begin{abstract}
A bulk magnet based on Sm-Fe-V with the $\mathrm{ThMn}_{12}$ crystal structure has been fabricated for the first time by hot-compaction of mechanically milled powders with a density of $92 \%$ of the theoretical density. The isotropic magnet exhibits a maximum coercivity of $1.06 \mathrm{~T}$ with a magnetization of $0.59 \mathrm{~T}$, a remanent magnetization of $0.42 \mathrm{~T}$ and $\mathrm{a}(B H)_{\max }$ of $28 \mathrm{~kJ} \mathrm{~m}^{-3}$ at $3 \mathrm{~T}$ applied field. The Curie temperature is found to be $330{ }^{\circ} \mathrm{C}$ and the temperature coefficients of remanent magnetization and coercivity are $0.14 \% \mathrm{C}^{-1}$ and $0.39 \% \mathrm{C}^{-1}$, respectively. Minor hysteresis loops indicate a coercivity mechanism similar to that of the nanocrystalline Nd-Fe-B magnets. The isotropic magnet was hot-deformed up to $75 \%$ of its height, and the best magnetic properties obtained were $\mu_{0} M_{3 \mathrm{~T}}=0.63 \mathrm{~T}, \mu_{0} M_{\mathrm{r}}=0.45 \mathrm{~T}, \mu_{0} H_{\mathrm{c}}=0.88 \mathrm{~T}$ and $(B H)_{\max }=33 \mathrm{~kJ} \mathrm{~m}^{-3}$. A small texture perpendicular to compaction direction was detected when the amount of vanadium was reduced, and the deformation temperature was increased from 800 to $1000{ }^{\circ} \mathrm{C}$.
\end{abstract}

\section{Keywords}

Permanent magnets, $\mathrm{ThMn}_{12}$, hot-compaction, mechanical milling, anisotropic magnet, hot-deformation 


\section{Introduction}

There is an increasing worldwide demand to minimize dependency on fossil fuels due to sustainability problems along with the drive to reduce carbon emissions by encouraging the use of wind energy and electric/hybrid vehicles. This is going to result in phenomenal increase in demand for high performance permanent magnets (PMs), an industry which is already under pressure due to the high demand, high rare-earth (RE) prices and volatile supply chain of critical metals such as $\mathrm{Dy}, \mathrm{Tb}$. In an effort to reduce RE-metals consumption, there has been a renewed interest in 1:12 compounds with $\mathrm{ThMn}_{12}$-type crystal structure (space group I4/mmm) [1-4]. These compounds contain only a $7.7 \%$ of $\mathrm{RE}$, compared with $11.8 \%$ in $\mathrm{RE}_{2} \mathrm{Fe}_{14} \mathrm{~B}$, and have a tetragonal structure, which is a requirement for uniaxial magnetocrystalline anisotropy (easy $c$-axis for $\mathrm{RE}=\mathrm{Sm}$ and easy plane for $\mathrm{RE}=\mathrm{Nd}$ ). The uniaxial anisotropy of the $\mathrm{Sm}$-based alloys makes them more suitable as starting materials for producing anisotropic permanent magnets than the Nd-based systems. The $\mathrm{REFe}_{12}$ binary compounds are not thermodynamically stable and do not exist in the bulk alloy form, but can be stabilized by adding a third element such as $\mathrm{Ti}, \mathrm{V}, \mathrm{Mo}, \mathrm{Cr}, \mathrm{W}$ or $\mathrm{Si}$ [5-7]. Intrinsic properties of these alloys have been investigated in depth in view of their interest as potentially suitable for permanent magnets processing [8-13]. The saturation magnetization $\left(M_{\mathrm{s}}\right)$, anisotropy field $\left(H_{\mathrm{A}}\right)$ and Curie temperature $\left(T_{\mathrm{C}}\right)$ of these 1:12 alloys are comparable to those of $\mathrm{Nd}_{2} \mathrm{Fe}_{14} \mathrm{~B}$. Hard magnetic properties with coercivity $\left(\mu_{0} H_{\mathrm{c}}\right)$ values ranging between 0.2 to $0.78 \mathrm{~T}$ were reported in melt-spun ribbons of $\mathrm{Sm}(\mathrm{Fe}, \mathrm{M})_{12}(\mathrm{M}=\mathrm{Ti}, \mathrm{Mo}, \mathrm{V})$ alloys [14-17]. Only a couple of studies have been reported on bulk magnets made out of 1:12 alloys. Shultz et al. [18] reported a $\mathrm{Sm}-\mathrm{Fe}-\mathrm{V}$ based resin bonded magnet with $1.17 \mathrm{~T}$ of coercivity prepared from the mechanically alloyed powders. Pinkerton et al. [14] reported a bulk magnet produced by hot pressing the $\mathrm{Sm}_{0.89} \mathrm{Fe}_{10} \mathrm{~V}_{2}$ melt spun ribbons at $850{ }^{\circ} \mathrm{C}$. However, the $\mu_{0} H_{\mathrm{c}}$ values obtained in the magnet was only $0.56 \mathrm{~T}$. The main challenge in making a magnet is to obtain 1:12 phase while suppressing the formation of $\alpha-(\mathrm{Fe}, \mathrm{M})$ because of the loss of Sm-metal during the various stages of processing due to evaporation and oxidation. Development of high $\mu_{0} H_{\mathrm{c}}$ in the alloy powders and optimizing the microstructure of the bulk sample and maintaining it throughout the processing is crucial. In this paper, we are reporting a process we developed to make a bulk magnet by using hot-compaction

of mechanically milled powders. Based on the previous reports on the intrinsic and hard magnetic properties of 1:12 compounds, we have chosen the Sm-Fe-V alloy [8,12,14,18-20]. We also report 
the thermal stability of $\mu_{0} H_{\mathrm{c}}$ and $\mu_{0} M_{\mathrm{r}}$ and results on our latest attempts to obtain an anisotropic magnet by hot-deformation.

\section{Experimental}

Ingots with nominal compositions $\mathrm{Sm}_{12} \mathrm{Fe}_{73} \mathrm{~V}_{15}$ and $\mathrm{Sm}_{12} \mathrm{Fe}_{76.5} \mathrm{~V}_{11.5}$ were prepared by arcmelting the pure elements Sm (pieces 99.9\%), Fe (pieces 99.97\%) and V (sheets 99.7\%) under Ar atmosphere. Excess of Sm was included in the alloy to prevent the Sm losses. The ingots were annealed in Ar to maximize the volume fraction of the 1:12 phase at different temperatures ranging from 800 to $1100^{\circ} \mathrm{C}$ for 2 days and quenched in water. The powders were milled in a SPEX mill unit using a custom-made hardened steel vial equipped with a vacuum valve, and steel balls of 12, 8,5 and $4 \mathrm{~mm}$ diameter under high purity argon. A ball to powder mass of 20:1 was used. The asmilled powders were hot-compacted at $650^{\circ} \mathrm{C}$ in vacuum using a tungsten carbide (WC) die by applying a pressure of $220 \mathrm{MPa}$. For hot-compaction, the sample was heated to $650{ }^{\circ} \mathrm{C}$ at a heating rate of $65^{\circ} \mathrm{C} \mathrm{min}-1$ and the pressure was applied for $13 \mathrm{~min}$. Finally, the sample was cooled to room temperature and a 92\%-dense isotropic magnet was obtained. The hot-compacted sample was then heat-treated at $700{ }^{\circ} \mathrm{C}$ for $10 \mathrm{~min}$ to $30 \mathrm{~min}$ to optimize the coercivity. To obtain an anisotropic magnet, the hot-compacted magnet was placed between alumina punches and then hotdeformed parallel to the press direction at $800{ }^{\circ} \mathrm{C}$. The pieces were hot-deformed up to $75 \%$ of their original height.
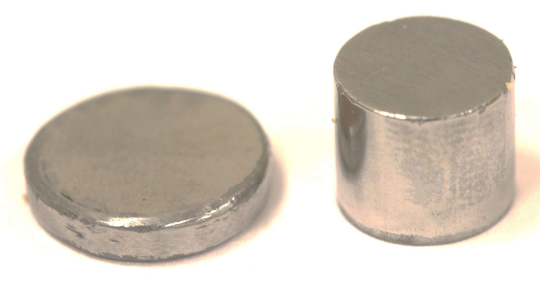

Fig. $1 \mathrm{Sm}-\mathrm{Fe}-\mathrm{V}$ based 1:12 hot-compacted and hot-deformed magnets

Hysteresis loops were measured with field applied parallel to the deformation direction (//) and the perpendicular direction $(\perp)$. A maximum field of $3 \mathrm{~T}$ was applied during the measurements, and the hysteresis loops were corrected for the self-demagnetization effect. 
Temperature coefficients of remanence $(\alpha)$, and coercivity $(\beta)$ in a temperature range from $T_{1}$ to $T_{2}$, defined as,

$$
\alpha \equiv \frac{M_{\mathrm{r}\left(T_{2}\right)}-M_{\mathrm{r}\left(T_{1}\right)}}{M_{\mathrm{r}\left(T_{1}\right)}} \frac{1}{\Delta T} \times 100 \% \quad \text { Eq. (1) }
$$

and

$$
\beta \equiv \frac{\mu_{0} H_{\mathrm{c}\left(T_{2}\right)}-\mu_{0} H_{\mathrm{c}\left(T_{1}\right)}}{\mu_{0} H_{\mathrm{c}\left(T_{1}\right)}} \frac{1}{\Delta T} x 100 \%, \quad \text { Eq. (2) }
$$

were calculated using the expressions,

$$
\alpha=\frac{a_{\mathrm{r}}\left(T_{2}+T_{1}\right)+b_{\mathrm{r}}}{M_{\mathrm{r}\left(T_{1}\right)}} \quad \text { Eq. (3) }
$$

and

$$
\beta=\frac{a_{\mathrm{c}}\left(T_{2}+T_{1}\right)+b_{\mathrm{c}}}{\mu_{0} H_{\mathrm{c}\left(T_{1}\right)}} \quad \text { Eq. (4) }
$$

where $a_{\mathrm{i}}$ and $b_{\mathrm{i}}(\mathrm{i}=\mathrm{r}, \mathrm{c})$ are the regression coefficients of the quadratic functions $M_{\mathrm{r}(T)}$ and $\mu_{0} H_{\mathrm{c}(T)}$. The crystal structure was studied by X-ray diffraction (XRD) using a Rigaku Ultima IV instrument with $\mathrm{Cu}-\mathrm{K} \alpha$ radiation. Lattice parameters and volume fractions of the different phases were calculated using Rietveld analysis [21]. Microstructure studies were performed using a JEOL (JSM- 6335F) scanning electron microscope (SEM).

\section{Results and discussion}

The XRD patterns of the $\mathrm{Sm}_{12} \mathrm{Fe}_{73} \mathrm{~V}_{15}$ sample at different stages of the processing are shown in Fig. 2. The homogenized ingot (Fig. 2(a)) shows reflections from the 1:12 phase (estimated volume fraction $84.9 \%), \mathrm{REFe}_{2}$ Laves phase (1:2) (14.3\%) and a small amount of $\alpha-(\mathrm{Fe}, \mathrm{V})$ phase $(0.8 \%)$; this was also confirmed by thermo-magnetic data. With milling, the peaks of both the 1:12 and 1:2 structures become very weak and broad, and after 10 hours of milling, a strong broad peak around $44.3^{\circ}$ is observed, along with an almost negligible broad halo peak overlapping the 1:12 and 1:2 peaks, as shown in Fig. 2(b). This indicates the formation of an amorphous phase coexisting with an $\alpha-(\mathrm{Fe}, \mathrm{V})$ phase. The small shift from the pure $\alpha$-Fe diffraction angle $\left(2 \theta=44.7^{\circ}\right)$ suggests a lattice expansion, this is a result from the solid solution of $\mathrm{V}$ atoms in the Fe-based bcc lattice. The hot-compacted magnet shows the presence of $1: 12$ and 1:2 phases along with a small amount of Sm oxides (Fig. 2(c)) possibly formed because the as-milled powder 
was exposed to the air. The hot-compacted sample shows very broad peaks indicating very fine grains. The hot-compacted sample subjected to an additional annealing at $700{ }^{\circ} \mathrm{C}$ for $30 \mathrm{~min}$ shows an XRD pattern with sharper and well-defined peaks compared with the previous stage, indicating an increase in the grain size. Refinement of the XRD patterns show the presence of the 1:12 phase (85.9\%), 1:2 (1.6\%), $\mathrm{SmO}$ (5.2\%), $\mathrm{Sm}_{2} \mathrm{O}_{3}(3.8 \%), \mathrm{Sm}(2.6 \%)$ and a very small amount of $\alpha-(\mathrm{Fe}, \mathrm{V})$ $(0.9 \%)$. As one can see, the amount of the $1: 2$ phase is reduced after processing by a $89 \%$, but the initial excess of Sm has prevented loss of the 1:12. The Rietveld refinement parameter can be found in the supplementary data.

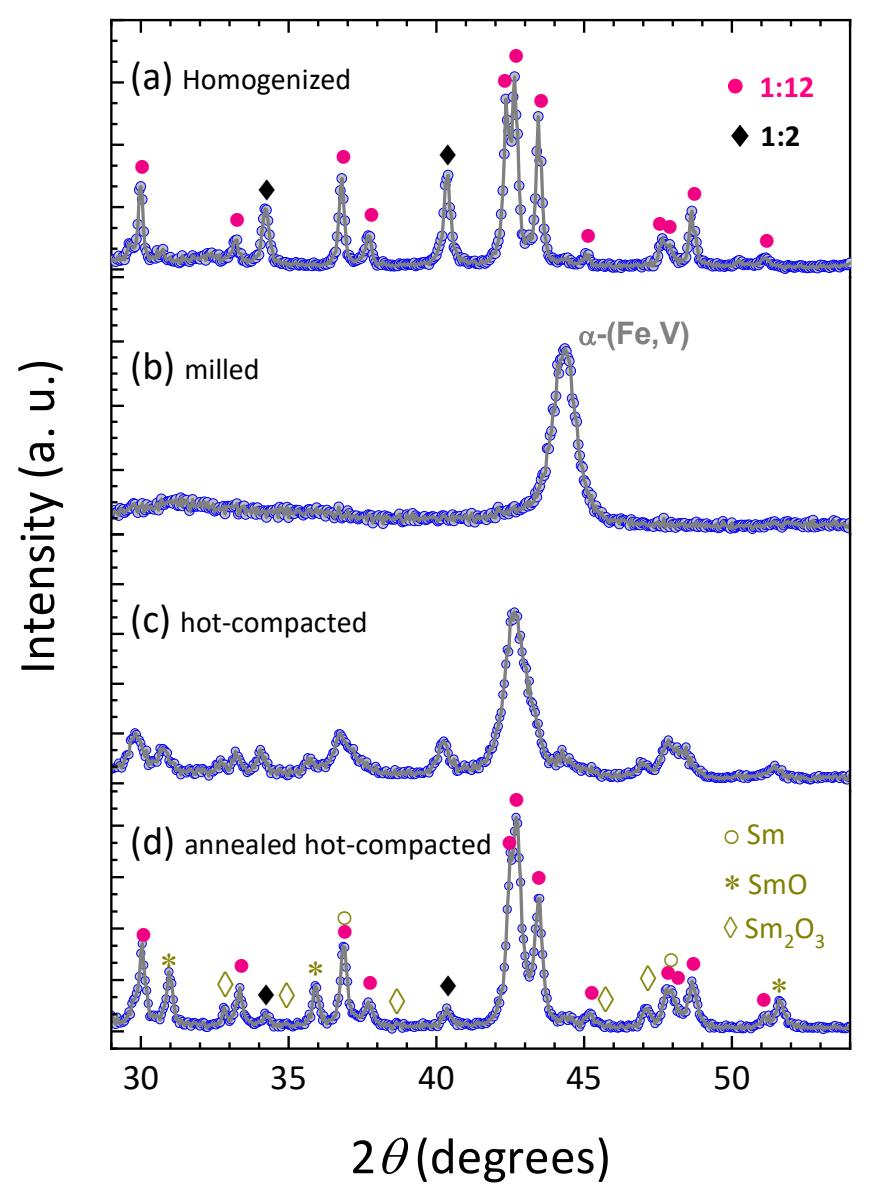

Fig. $2 \mathrm{X}$-ray diffraction patterns of the $\mathrm{Sm}_{12} \mathrm{Fe}_{73} \mathrm{~V}_{15}$ samples (a) homogenized at $800^{\circ} \mathrm{C}$ (b) after milling (c) hot-compacted and (d) annealed hot-compacted. 
Fig. 3 shows the evolution of the hysteresis loops measured by applying a maximum field of $3 \mathrm{~T}$ at room temperature for the homogenized, as milled, hot-compacted and the annealed hot-compacted samples. Table 1 summarizes the values of $\mu_{0} H_{\mathrm{c}}, \mu_{0} M_{3 \mathrm{~T}}$ and $\mu_{0} M_{\mathrm{r}}$.

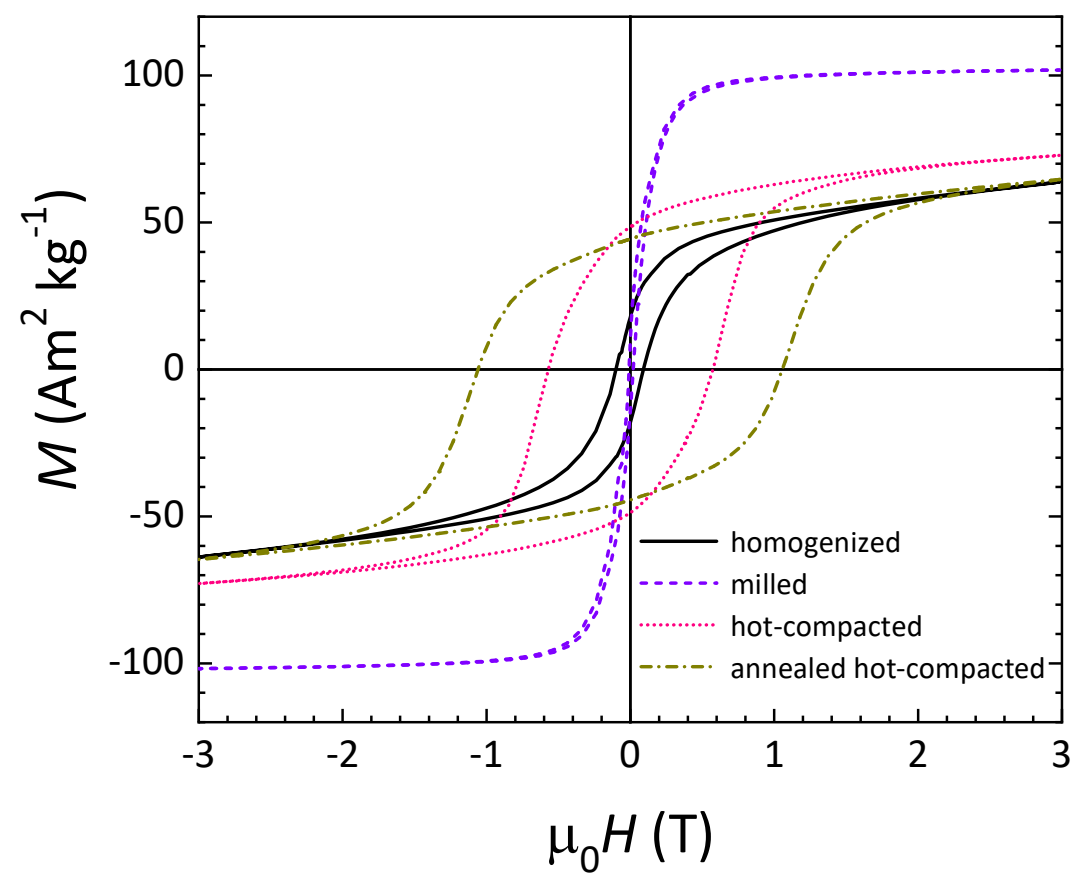

Fig. 3 Hysteresis loops of the $\mathrm{Sm}_{12} \mathrm{Fe}_{73} \mathrm{~V}_{15}$ homogenized, after milling for $10 \mathrm{~h}$, hot-compacted and annealed hot-compacted samples.

The homogenized sample shows $\mu_{0} H_{\mathrm{c}}$ and $\mu_{0} M_{3 \mathrm{~T}}$ of $0.09 \mathrm{~T}$ and $0.62 \mathrm{~T}\left(64 \mathrm{Am}^{2} \mathrm{~kg}^{-1}\right)$, respectively. After milling, the value of $\mu_{0} M_{3 \mathrm{~T}}$ increases to $\left(102 \mathrm{Am}^{2} \mathrm{~kg}^{-1}\right)$ and the $\mu_{0} H_{\mathrm{c}}$ was measured to be $0.02 \mathrm{~T}$, which is due to the absence of high-anisotropy phase and large volume fraction of the $\alpha-(\mathrm{Fe}, \mathrm{V})$ solid solution. Optimal heat-treatment of the hot-compacted magnet results in an increase of $\mu_{0} H_{\mathrm{c}}$ to $1.06 \mathrm{~T}$, the highest value reported so far in 1:12 bulk magnets. The $\mu_{0} M_{3 \mathrm{~T}}, \mu_{0} M_{\mathrm{r}}$ and $(B H)_{\max }$ are found to be $0.59 \mathrm{~T}\left(64 \mathrm{Am}^{2} \mathrm{~kg}^{-1}\right), 0.42 \mathrm{~T}\left(46 \mathrm{Am}^{2} \mathrm{~kg}^{-1}\right)$ and $28 \mathrm{~kJ} \mathrm{~m}^{-3}$ (3.5 MGOe). The hysteresis loops of the hot-compacted and annealed hot-compacted sample do not show any zero-field steps which could indicate presence of the soft magnetic $\alpha-(\mathrm{Fe}, \mathrm{V})$ phase, which is consistent with the XRD results.

We obtained greater coercivity and better loop rectangularity than Pinkerton and Van Wingerden [30] in the only earlier reported fully dense Sm-Fe-V magnet $\left(\mu_{0} H_{\mathrm{c}}=0.56 \mathrm{~T}\right.$, 
$\mu_{0} M_{\mathrm{r}}=0.54 \mathrm{~T}$ in $\mathrm{Sm}_{15} \mathrm{Fe}_{70} \mathrm{~V}_{15}$ ). The improvement may be due to the use of high-energy milling for manufacturing the nanocrystalline precursor material rather than the melt-spinning. Indeed, the coercivity values achieved in this work are similar to those reported by Schultz et al. [18] $\left(\mu_{0} H_{\mathrm{c}}=1.17 \mathrm{~T}, \mu_{0} M_{\mathrm{r}}=0.49 \mathrm{~T}\right.$ in $\left.\mathrm{Sm}_{15} \mathrm{Fe}_{70} \mathrm{~V}_{15}\right)$ who employed mechanical alloying but did not prepare a fully dense magnet. On the other hand, the higher remanence values reported by Ding and Rosenberg [16] for melt-spun Sm-Fe-Co-V alloys indicate that a partial Co substitution for Fe may increase the energy density of the fully dense Sm-Fe-V magnets even in the absence of the crystallographic texture.

Table 1. Magnetic properties of the $\mathrm{Sm}_{12} \mathrm{Fe}_{73} \mathrm{~V}_{15}$ sample at different stages of processing. Values of $\mu_{0} H_{\mathrm{c}}$, $\mu_{0} M_{3 \mathrm{~T}}$ and $\mu_{0} M_{\mathrm{r}}$ in the parenthesis are given in $\mathrm{Am}^{2} \mathrm{~kg}^{-1}$. The value of $(B H)_{\max }$ in parenthesis is given in MGOe.

\begin{tabular}{|l|c|c|c|c|}
\hline \multicolumn{1}{|c|}{ Stage } & $\begin{array}{c}\mu_{\mathbf{0}} \boldsymbol{H}_{\mathbf{c}} \\
(\mathbf{T})\end{array}$ & $\begin{array}{c}\mu_{\mathbf{0}} \boldsymbol{M}_{\mathbf{3} \mathbf{T}} \\
\mathbf{( ~ T} \mathbf{~}\end{array}$ & $\begin{array}{c}\mu_{\mathbf{0}} \boldsymbol{M}_{\mathbf{r}} \\
\mathbf{( ~ T})\end{array}$ & $\begin{array}{c}(B H)_{\mathbf{m a x}} \\
\left(\mathbf{k J} / \mathbf{m}^{\mathbf{3}}\right)\end{array}$ \\
\hline Homogenized & 0.09 & $\begin{array}{c}0.62 \\
(64)\end{array}$ & $\begin{array}{c}0.25 \\
(26)\end{array}$ & $\begin{array}{c}4 \\
(0.5)\end{array}$ \\
\hline Milled & 0.02 & $-(102)$ & $-(7)$ & - \\
\hline Hot-compacted & 0.57 & $\begin{array}{c}0.64 \\
(74)\end{array}$ & $\begin{array}{c}0.45 \\
(51)\end{array}$ & $\begin{array}{c}31 \\
(3.8)\end{array}$ \\
\hline $\begin{array}{l}\text { Annealed hot- } \\
\text { compacted }\end{array}$ & 1.06 & $\begin{array}{c}0.59 \\
(64)\end{array}$ & $\begin{array}{c}0.42 \\
(46)\end{array}$ & $\begin{array}{c}28 \\
(3.5)\end{array}$ \\
\hline
\end{tabular}

In order to study the coercivity mechanism, the virgin and demagnetization curves are measured and shown in Fig. 4. The virgin magnetization curve shows a susceptibility that increases with the applied field going through a maximum at $0.9 \mathrm{~T}$, a field comparable with the maximum coercivity of the sample, consistent with the fact that the maximum amount of reversals occurs at this field. The susceptibility falls off again as the magnetization is approaching to saturation at high fields. The dependence of coercivity and remanent magnetization on applied field $\mu_{0} H_{\mathrm{m}}$, which is determined from the demagnetization curves, are plotted in the inset of Fig 4. The remanent magnetization and coercivity curves show a similar behavior, showing a small initial increase with $\mu_{0} H_{\mathrm{m}}$ until $\mu_{0} H_{\mathrm{m}}$ becomes comparable to the coercivity, whereupon both $\mu_{0} H_{\mathrm{c}}$ and 
$M_{\mathrm{r}}$ increase dramatically to saturation. This kind of behavior is characteristic of isotropic hard nanocrystalline materials (like Nd-Fe-B). The mechanisms of domain wall-pinning [21-26] and nucleation of reversed domains cannot be ruled out completely.

Thermomagnetic data measured on the optimally annealed compacted sample, show the $T_{\mathrm{C}}$ of the $1: 12$ phase to be $330{ }^{\circ} \mathrm{C}$; there is also another minority phase with $T_{\mathrm{C}}$ at $411{ }^{\circ} \mathrm{C}$, which is attributed to the $1: 2$ phase.

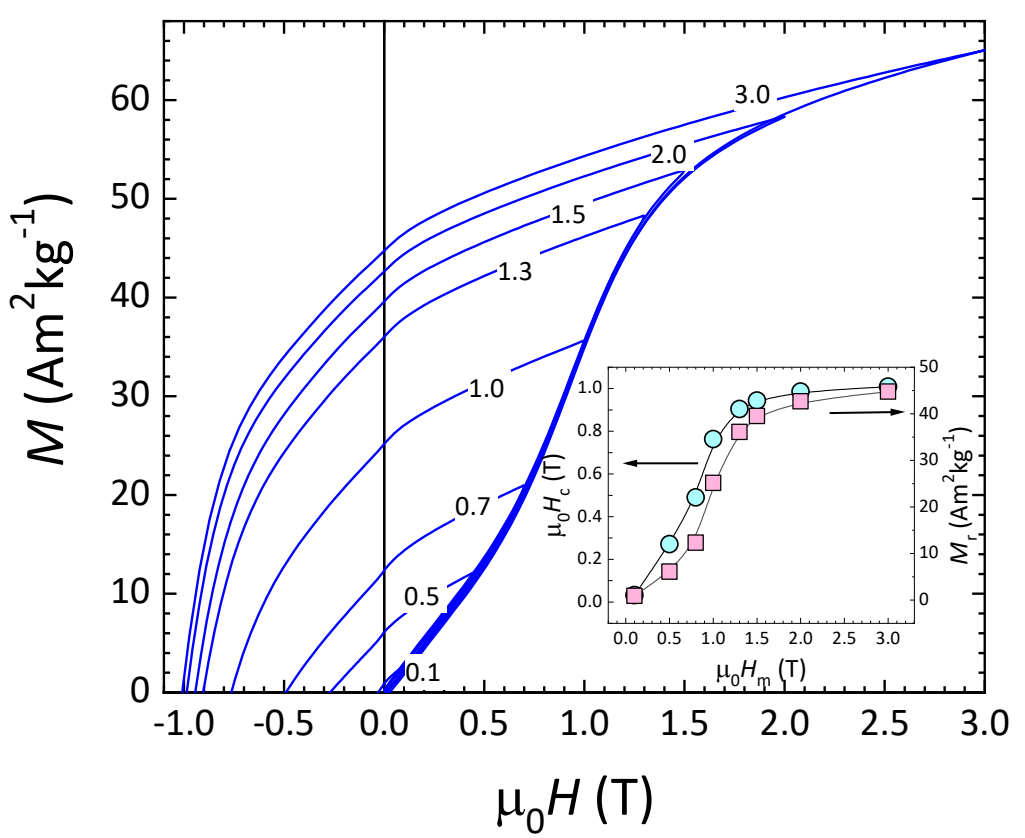

Fig. 4 Virgin and demagnetization curves at room temperature of the annealed hot-compacted $\mathrm{Sm}_{12} \mathrm{Fe}_{73} \mathrm{~V}_{15}$ magnet. The field value on each demagnetization curve is the maximum applied field in teslas. The sample was thermally demagnetized before the measurement of each curve.

Fig. 5(a) shows the second quadrant of M-H hysteresis loops at temperatures ranging from 223 to $327{ }^{\circ} \mathrm{C}$ for the annealed hot-compacted magnet. The temperature dependence of $\mu_{0} M_{\mathrm{r}}$ and $\mu_{0} H_{\mathrm{c}}$, are shown in Fig. 5(b). Here, $\mu_{0} H_{\mathrm{c}}$ and $\mu_{0} M_{\mathrm{r}}$ decreases with increasing temperature, and ultimately the $\mu_{0} M_{\mathrm{r}}$ becomes zero at the $T_{C}$ of the $1: 12$ phase $\left(330{ }^{\circ} \mathrm{C}\right)$. Similarly, to the Nd-Fe-B magnets [22], the decrease in $\mu_{0} H_{\mathrm{c}}$ is more prominent than $\mu_{0} M_{\mathrm{r}}$. The values of $\mu_{0} H_{\mathrm{c}}$ and $\mu_{0} M_{\mathrm{r}}$ are found to be $2.6 \mathrm{~T}$ and $0.5 \mathrm{~T}\left(51 \mathrm{Am}^{2} \mathrm{~kg}^{-1}\right)$ at $-223{ }^{\circ} \mathrm{C}$ and $0.5 \mathrm{~T}$ and $0.3 \mathrm{~T}\left(33 \mathrm{Am}^{2} \mathrm{~kg}^{-1}\right)$ at $177{ }^{\circ} \mathrm{C}$, respectively. Temperature coefficients $\alpha$ and $\beta$, are calculated using eq. (3) and (4). The 
coefficients of the polynomial regressions and $r$-square are shown in Table 2 . The absolute values of $\alpha$ and $\beta$ at temperature range from $20{ }^{\circ} \mathrm{C}$ to $100{ }^{\circ} \mathrm{C}$ are $0.14 \% \mathrm{C}^{-1}$ and $0.39 \% \mathrm{C}^{-1}$, respectively. The coefficient $\beta$ is significantly lower than that of standard Nd-Fe-B sintered or hot-deformed magnets, which is above $0.55 \%{ }^{\circ} \mathrm{C}^{-1}[21,22]$.
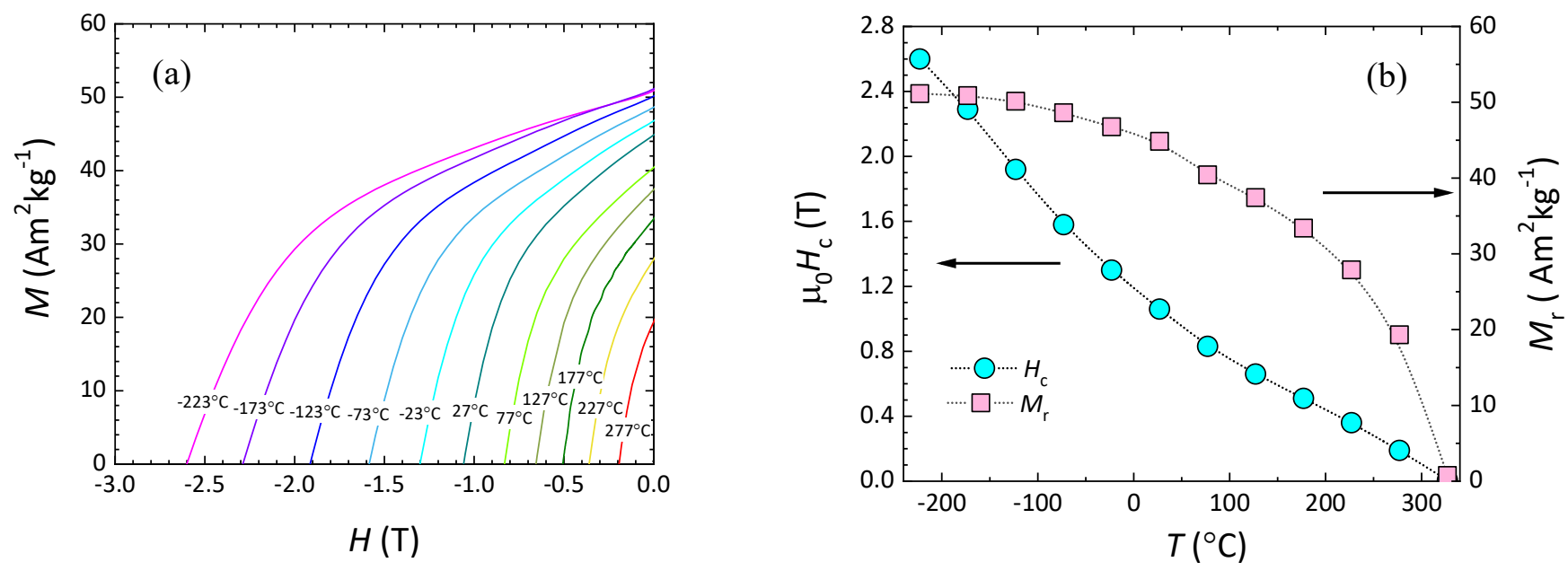

Fig. 5 (a) Demagnetization curves measured at different temperatures and (b) temperature dependence of coercivity and remanence of the annealed hot-compacted $\mathrm{Sm}_{12} \mathrm{Fe}_{73} \mathrm{~V}_{15}$ magnet.

Table 2. The coefficients and r-square from the polynomial regression of $M_{\mathrm{r}(T)}=a_{\mathrm{r}} T^{2}+b_{\mathrm{r}} T+c_{\mathrm{r}}$ and $\mu_{0} H_{\mathrm{c}(T)}=a_{\mathrm{c}} T^{2}+b_{\mathrm{c}} T+c_{\mathrm{c}}$ for temperature range $20-100{ }^{\circ} \mathrm{C}$ for the data plotted in Fig. $5(\mathrm{~b})$.

\begin{tabular}{|c|c|c|c|c|}
\hline & $a_{\mathrm{i}}\left(x 10^{-4}{ }^{\circ} \mathrm{C}^{-2}\right)$ & $b_{\mathrm{i}}\left({ }^{\circ} \mathrm{C}^{-1}\right)$ & $c_{\mathrm{i}}$ & $r^{2}$ \\
\hline$M_{\mathrm{r}}$ & $-1.20 \mathrm{Am}^{2} \mathrm{~kg}^{-1}$ & $-0.0505 \mathrm{Am}^{2} \mathrm{~kg}^{-1}$ & $45.7 \mathrm{Am}^{2} \mathrm{~kg}^{-1}$ & 0.99803 \\
\hline$\mu_{0} H_{\mathrm{c}}$ & $0.0687 \mathrm{~T}$ & $0.00512 \mathrm{~T}$ & $1.19 \mathrm{~T}$ & 0.99964 \\
\hline
\end{tabular}

Fig. 6 shows the SEM secondary-electrons image taken from the fractured surface of the hot compacted magnet. The average grain size of the hot compacted magnet was estimated to be $13 \pm 3 \mathrm{~nm}$. The high $\mu_{0} H_{\mathrm{c}}$ obtained in this sample could be attributed to the very fine grain size of the highly anisotropic 1:12 phase, also It seems to be that the as-milled structure aids to the formation of a very fine grain microstructure of 1:12 phase during the hot-compaction. 


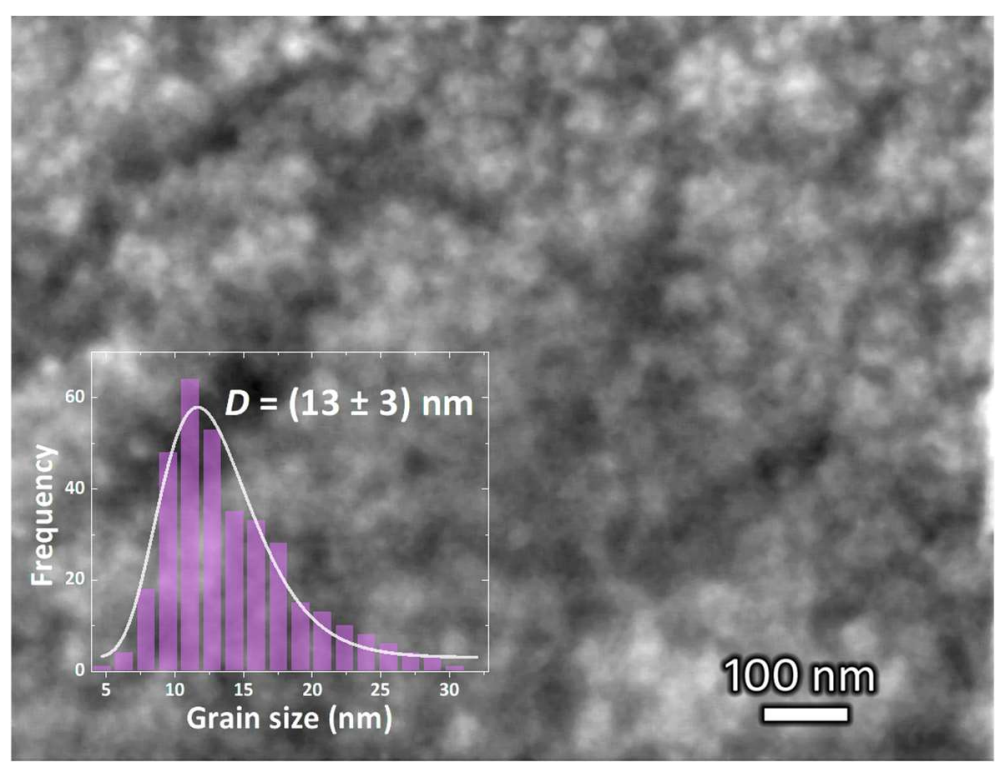

Fig. 6. SEM secondary electrons-image of the fractured surface of the hot-compacted $\mathrm{Sm}_{12} \mathrm{Fe}_{73} \mathrm{~V}_{15}$ magnet.

Hysteresis loops of $\mathrm{Sm}_{12} \mathrm{Fe}_{73} \mathrm{~V}_{15}$ and. $\mathrm{Sm}_{12} \mathrm{Fe}_{76.5} \mathrm{~V}_{115}$ hot deformed magnets measured parallel (II) and perpendicular $(\perp)$ to the compression direction $\Delta L$ are shown in Fig 7(a) and 7(b), respectively. The magnetic properties are listed in Table 3. After deformation of $\mathrm{Sm}_{12} \mathrm{Fe}_{73} \mathrm{~V}_{15}$ sample at $800{ }^{\circ} \mathrm{C}, \mu_{0} M_{3 \mathrm{~T}}$ remains almost unchanged at $0.63 \mathrm{~T}\left(66.4 \mathrm{Am}^{2} \mathrm{~kg}^{-1}\right)$ and the $\mu_{0} H_{\mathrm{c}}$ is increased to $0.88 \mathrm{~T}$ compared with the hot-compacted magnet. An $\mu_{0} M_{\mathrm{r}}$ value of $0.45 \mathrm{~T}$ $\left(47 \mathrm{Am}^{2} \mathrm{~kg}^{-1}\right)$ and $0.42 \mathrm{~T}\left(44 \mathrm{Am}^{2} \mathrm{~kg}^{-1}\right)$ are obtained when the hysteresis loops were measured with field applied $\perp$ and $\|$ directions, respectively, indicating a small degree of anisotropy (DOA) development in the plane perpendicular to the deformation, this is in contrary to that of $\mathrm{Nd}_{2} \mathrm{Fe}_{14} \mathrm{~B}$ based hot-deformed magnets, where the $c$-axis of grains aligns along the press direction [23,24]. The DOA was calculated using the formula DOA $=\left(\mu_{0} M_{\mathrm{r}^{\perp}}{ }^{-} \mu_{0} M_{\mathrm{r}}{ }^{\|}\right) / \mu_{0} M_{\mathrm{r}^{\perp}}$, where $\mu_{0} M_{\mathrm{r}^{\perp}}{ }^{\perp}$ is the remanence measured $\perp$ to the deformation and $\mu_{0} M_{\mathrm{r}} \|$ measured $\|$ to the deformation. The deformed magnet shows a DOA value of 0.095 . The $\mu_{0} M_{\mathrm{r}}$ and $(B H)_{\max }$ of $0.45 \mathrm{~T}\left(47 \mathrm{Am}^{2} \mathrm{~kg}^{-1}\right)$ and $33 \mathrm{~kJ} / \mathrm{m}^{3}$ (4.1 MGOe) were obtained from the hysteresis loop measured in $\perp$ direction. When $\mathrm{V}$ is reduced from 15 to 11.5 at.\%, and the $\mathrm{Sm}_{12} \mathrm{Fe}_{76.5} \mathrm{~V}_{11.5}$ isotropic hot-compacted magnet is deformed at $1000{ }^{\circ} \mathrm{C}$ (see Fig. 7(b)), there is a noticeable increase in the DOA to 0.286 resulting in $\mu_{0} M_{\mathrm{r}}^{\perp}$ of $0.47 \mathrm{~T}\left(52 \mathrm{Am}^{2} \mathrm{~kg}^{-1}\right)$ and $\mu_{0} H_{\mathrm{c}}$ of $0.41 \mathrm{~T}$. The XRD results indicate that the recrystallization is completed, and grain growth takes place during the exposure to the high deformation temperature. 

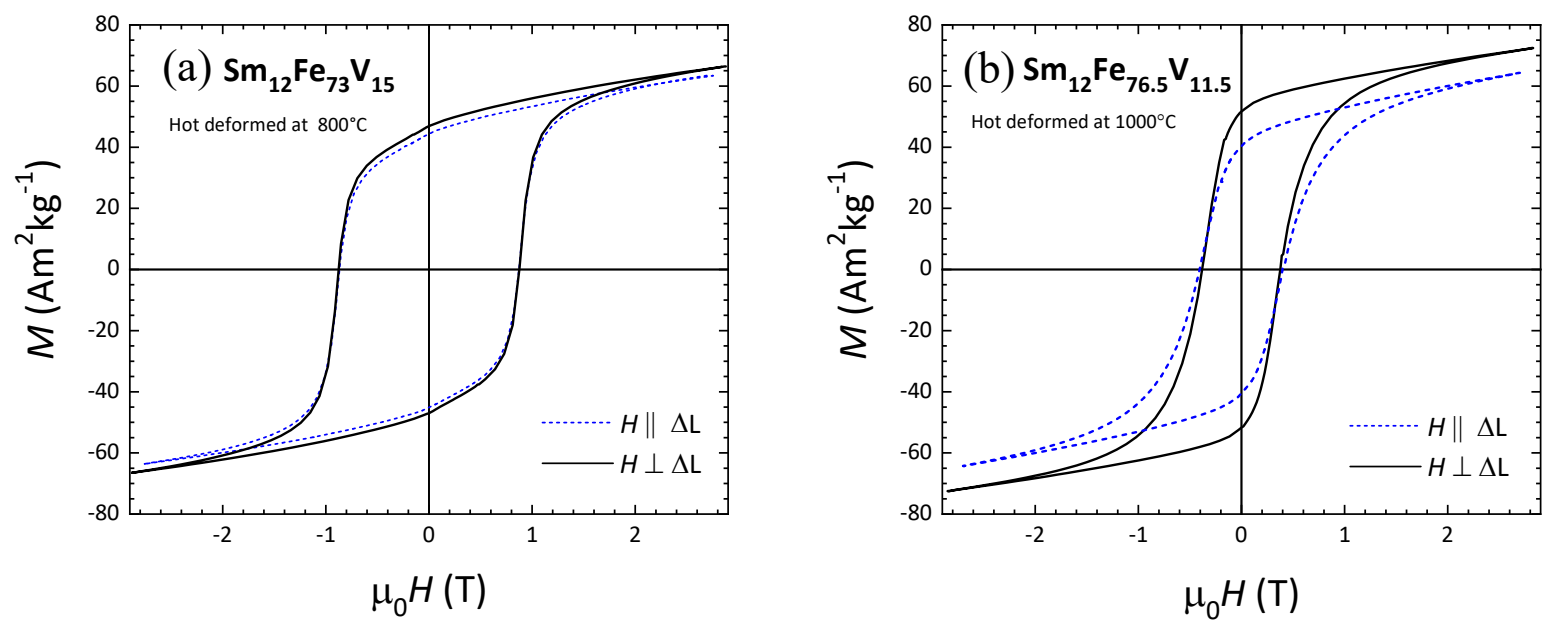

Fig. 7: Hysteresis loops of the hot-deformed magnet measured parallel $(\|)$ and perpendicular $(\perp)$ to the deformation (a) $\mathrm{Sm}_{12} \mathrm{Fe}_{73} \mathrm{~V}_{15}$ (b) $\mathrm{Sm}_{12} \mathrm{Fe}_{76.5} \mathrm{~V}_{11.5}$.

Table 3. Magnetic properties of $\mathrm{Sm}_{12} \mathrm{~F}_{73} \mathrm{~V}_{15}$ and $\mathrm{Sm}_{12} \mathrm{~F}_{76.5} \mathrm{~V}_{11.5}$ deformed magnets. Values in parenthesis are given in $\mathrm{Am}^{2} \mathrm{~kg}^{-1}$. The value of $(B H)_{\max }$ in parenthesis is given in MGOe.

\begin{tabular}{|c|c|c|c|c|c|c|}
\hline Magnet & $\begin{array}{c}T_{\text {deform }} \\
\left({ }^{\circ} \mathrm{C}\right)\end{array}$ & $\begin{array}{c}\mu_{0} M_{r^{\perp}} \\
(\mathbf{T})\end{array}$ & $\begin{array}{c}\mu_{0} M_{r} \| \\
(\mathbf{T})\end{array}$ & DOA & $\begin{array}{r}\mu_{0} H_{c} \\
(\mathbf{T})\end{array}$ & $\begin{array}{l}(B H)_{\text {max }} \\
\left(\mathbf{k J} / \mathrm{m}^{3}\right)\end{array}$ \\
\hline $\mathrm{Sm}_{12} \mathrm{~F}_{73} \mathrm{~V}_{15}$ & 800 & $\begin{array}{l}0.45 \\
(47)\end{array}$ & $\begin{array}{l}0.42 \\
(44)\end{array}$ & 0.095 & 0.88 & $\begin{array}{c}33 \\
(4.1)\end{array}$ \\
\hline $\mathrm{Sm}_{12} \mathrm{~F}_{76.5} \mathrm{~V}_{11.5}$ & 1000 & $\begin{array}{l}0.47 \\
(52)\end{array}$ & $\begin{array}{l}0.37 \\
(40)\end{array}$ & 0.286 & 0.41 & $\begin{array}{c}29 \\
(3.7)\end{array}$ \\
\hline
\end{tabular}




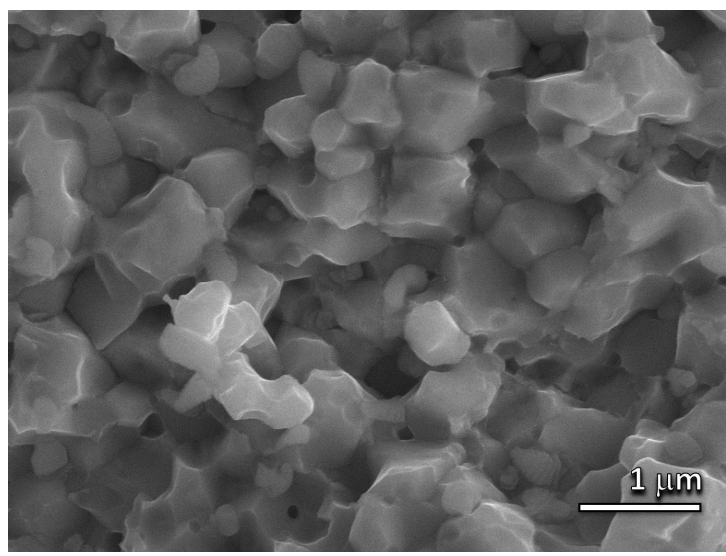

Fig. 8. Microstructure of $\mathrm{Sm}_{12} \mathrm{Fe}_{76.5} \mathrm{~V}_{11.5}$ magnet deformed at $1000{ }^{\circ} \mathrm{C}$.

Much larger grains, ranging between $0.3 \mu \mathrm{m}$ and $1 \mu \mathrm{m}$, are observed (Fig. 8), which explain the markedly lower $\mu_{0} H_{\mathrm{c}}$ of $0.41 \mathrm{~T}$. Although texture is evident from the magnetic measurements, the 1:12 grains maintain a nearly equiaxed morphology (unlike, for example, the $\mathrm{Nd}_{2} \mathrm{Fe}_{14} \mathrm{~B}$ grains in the hot-deformed $\mathrm{Nd}-\mathrm{Fe}-\mathrm{B}$ magnets [25]). The texture is similar to that of observed in Mn-Al hot-deformed magnets [26,27]. The magnets developed in this study exhibit optimal magnetic properties in every direction perpendicular to the deformation direction. These magnets are suitable for motor-generator applications where circumferential multipole magnets are used. In 1:12 magnets, uniaxial texture may be possible by hot-extrusion as it was obtained in the case of Mn-Al magnets [28,29].

\section{Conclusions}

We have succeeded in fabricating, for the first time, a bulk $\mathrm{Sm}(\mathrm{Fe}, \mathrm{V})_{12}$ based nanocrystalline magnet by hot-compaction of mechanically milled powders, with a $\mu_{0} H_{\mathrm{c}}=1.06 \mathrm{~T}$ and $(B H)_{\max }=28 \mathrm{~kJ} \mathrm{~m}^{-3}$. The $T_{\mathrm{C}}$ was $330^{\circ} \mathrm{C}$ and the temperature coefficients $\alpha=0.14 \% \mathrm{C}^{-1}$ and $\beta=0.39 \% \mathrm{C}^{-1}$. The $\beta$ value is comparatively lower than that of $\mathrm{NdFeB}$ magnets. A texture perpendicular to the deformation direction was observed. This kind of behavior is different from that of die-upset Nd-Fe-B magnets and would indicate the use of hot extrusion rather than dieupsetting for the development of bulk magnets. These results encourage the study on highly 
textured ultrafine-grained magnets, reopening the development of 1:12 Sm-based anisotropic magnets.

\section{Acknowledgements}

This work was supported by the Novamag and Inapem projects under EU Horizon 2020

Programme (grants 686056 and 691235) and the U.S. Department of Energy (DOE DE-FG0290ER45413). 


\section{References}

[1] I.S. Tereshina, N. V. Kostyuchenko, E.A. Tereshina-Chitrova, Y. Skourski, M. Doerr, I.A. Pelevin, A.K. Zvezdin, M. Paukov, L. Havela, H. Drulis, ThMn 12 -type phases for magnets with low rare-earth content: Crystal-field analysis of the full magnetization process, Sci. Rep. 8 (2018) 8-13. doi:10.1038/s41598-018-21756-5.

[2] Y. Hirayama, Y.K. Takahashi, S. Hirosawa, K. Hono, Scripta Materialia Intrinsic hard magnetic properties of $\mathrm{Sm}\left(\mathrm{Fe}_{1-\mathrm{x}} \mathrm{Co}_{\mathrm{x}}\right)_{12}$ compound with the $\mathrm{ThMn}_{12}$ structure, Scr. Mater. 138 (2017) 62-65. doi:10.1016/j.scriptamat.2017.05.029.

[3] A.M. Gabay, R. Cabassi, S. Fabbrici, F. Albertini, G.C. Hadjipanayis, Structure and permanent magnet properties of $\mathrm{Zr}_{1-\mathrm{x}} \mathrm{R}_{\mathrm{x}} \mathrm{Fe}_{10} \mathrm{Si}_{2}$ alloys with $\mathrm{R}=\mathrm{Y}$, La, Ce, Pr and $\mathrm{Sm}, \mathrm{J}$. Alloys Compd. 683 (2016) 271-275. doi:10.1016/j.jallcom.2016.05.092.

[4] S. Suzuki, T. Kuno, K. Urushibata, K. Kobayashi, N. Sakuma, K. Washio, M. Yano, A. Kato, A. Manabe, A new magnet material with $\mathrm{ThMn}_{12}$ structure: $\left(\mathrm{Nd}_{1-\mathrm{x}} \mathrm{Zr}_{\mathrm{x}}\right)\left(\mathrm{Fe}_{1-}\right.$ $\left.{ }_{\mathrm{y}} \mathrm{Co}_{\mathrm{y}}\right)_{11+\mathrm{z}} \mathrm{Ti}_{1-\mathrm{z}} \mathrm{N}_{\alpha}(\alpha=0.6-1.3)$, J. Magn. Magn. Mater. 401 (2016) 259-268. doi:10.1016/j.jmmm.2015.10.042.

[5] K.H.J. Buschow, Permanent magnet materials based on tetragonal rare earth compounds of the type $\mathrm{RFe}_{12-\mathrm{x}} \mathrm{M}_{\mathrm{x}}$, J. Magn. Magn. Mater. 100 (1991) 79-89. doi:10.1016/03048853(91)90813-P.

[6] A.M. Gabay, G.C. Hadjipanayis, Recent developments in $\mathrm{RFe}_{12}$-type compounds for permanent magnets, Scr. Mater. 154 (2018) 284-288.

doi:10.1016/j.scriptamat.2017.10.033.

[7] R. Madugundo, N.V.R. Rao, A.M. Schönhöbel, D. Salazar, A. A. El-Gendy, Recent Developments in Nanostructured Permanent Magnet Materials and Their Processing Methods, in: A. El-Gendy, J.M. Barandiaran, R.L. Hadimani (Eds.), Magn.

Nanostructured Mater. From Lab to Fab, 1st ed., Elsevier, Amsterdam, Netherlands, 2018: pp. 157-198.

[8] F.R. De Boer, Y.-K. Huang, D.B. De Mooij, K.H.J. Buschow, Magnetic properties of a series of novel ternary intermetallics $\left(\mathrm{RFe}_{10} \mathrm{~V}_{2}\right)$, J. Less Common Met. 135 (1987) 199204. doi:10.1016/0022-5088(87)90481-4.

[9] K.H.J. Buschow, D.B. de Mooij, M. Brouha, H.H. Smit, R.C. Thiel, Magnetic properties of ternary Fe-rich rare earth intermetallic compounds, IEEE Trans. Magn. 24 (1988) 1611-1616. doi:10.1109/20.11547.

[10] K. Ohashi, Y. Tawara, R. Osugi, J. Sakurai, Y. Komura, Identification of the intermetallic compound consisting of Sm, Ti, Fe, J. Less Common Met. 139 (1988) L1-L5. doi:10.1016/0022-5088(88)90020-3.

[11] Y. Wang, G.C. Hadjipanayis, A. Kim, N.C. Liu, D.J. Sellmyer, Magnetic and structural studies in Sm-Fe-Ti magnets, J. Appl. Phys. 67 (1990) 4954-4956. doi:10.1063/1.344745.

[12] Y.Z. Wang, G.C. Hadjipanayis, Effect of nitrogen on the structural and magnetic properties of intermetallic compounds with the $\mathrm{ThMn}_{12}$ structure, J. Appl. Phys. 70 (1991) 
6009-6011. doi:10.1063/1.350076.

[13] P. Tozman, H. Sepehri-Amin, Y.K. Takahashi, S. Hirosawa, K. Hono, Intrinsic magnetic properties of $\mathrm{Sm}\left(\mathrm{Fe}_{1-\mathrm{x}} \mathrm{Co}_{\mathrm{x}}\right)_{11} \mathrm{Ti}$ and $\mathrm{Zr}$-substituted $\mathrm{Sm}_{1-\mathrm{y}} \mathrm{Zr}_{\mathrm{y}}\left(\mathrm{Fe}_{0.8} \mathrm{Co}_{0.2}\right)_{11.5} \mathrm{Ti}_{0.5}$ compounds with $\mathrm{ThMn}_{12}$ structure toward the development of permanent magnets, Acta Mater. 153 (2018) 354-363. doi:10.1016/j.actamat.2018.05.008.

[14] F.E. Pinkerton, D.J. Van Wingerden, Magnetic hardening of $\mathrm{SmFe}_{10} \mathrm{~V}_{2}$ by melt-spinning, IEEE Trans. Magn. 25 (1989) 3306-3308. doi:10.1109/20.42285.

[15] M. Okada, K. Yamagishi, M. Homma, High Coercivity in Melt-Spun $\mathrm{SmFe}_{10}(\mathrm{TiV})_{2}$ Ribbons, Mater. Trans. JIM. 30 (1989) 374-377. doi:10.2320/matertrans 1989.30.374.

[16] J. Ding, M. Rosenberg, Magnetic hardening of melt-spun and crystallized Sm-Fe-V and Sm-(Fe, Co)-V alloys, J. Less-Common Met. 161 (1990) 369-374. doi:10.1016/00225088(90)90049-P.

[17] J. Wecker, M. Katter, K. Schnitzke, L. Schultz, Magnetic hardening of Sm-Fe-Ti alloys, J. Appl. Phys. 67 (1990) 4951-4953. doi:10.1063/1.344744.

[18] L. Schultz, K. Schnitzke, J. Wecker, High coercivity in mechanically alloyed Sm-Fe-V magnets with a ThMn 12 crystal structure, Appl. Phys. Lett. 56 (1990) 868-870. doi:10.1063/1.102662.

[19] K. Ohashi, Y. Tawara, R. Osugi, M. Shimao, Magnetic properties of Fe-rich rare-earth intermetallic compounds with a ThMn 12 structure, J. Appl. Phys. 64 (1988) 5714-5716. doi:10.1063/1.342235.

[20] J. Yang, S. Dong, Y. Yang, B. Cheng, Structural and magnetic properties of $\mathrm{RFe}_{10.5} \mathrm{~V}_{1.5} \mathrm{~N}_{\mathrm{x}}$, J. Appl. Phys. 75 (1994) 3013-3016. doi:10.1063/1.356168.

[21] H.M. Rietveld, A profile refinement method for nuclear and magnetic structures, J. Appl. Crystallogr. 2 (1969) 65-71. doi:10.1107/S0021889869006558.

[22] B.M. Ma, W.L. Liu, Y.L. Liang, D.W. Scott, C. Bounds, Comparison of the improvement of thermal stability of NdFeB sintered magnets: Intrinsic and / or microstructural, J. Appl. Phys. 75 (1994) 6628-6630.

[23] H.T. Kim, Y.B. Kim, H.S. Kim, Magnetic properties and texture of NdFeB magnets fabricated by current-applied-pressure-assisted process, J. Magn. Magn. Mater. 224 (2001) 173-179. doi:10.1016/S0304-8853(01)00018-X.

[24] K. Khlopkov, O. Gutfleisch, R. Schäfer, D. Hinz, K.H. Müller, L. Schultz, Interaction domains in die-upset $\mathrm{NdFeB}$ magnets in dependence on the degree of deformation, $\mathrm{J}$. Magn. Magn. Mater. 272-276 (2004) 2003-2005. doi:10.1016/j.jmmm.2003.12.1102.

[25] R. Lee, E. Brewer, N. Schaffel, Processing of Neodymium-Iron-Boron melt-spun ribbons to fully dense magnets, IEEE Trans. Magn. 21 (1985) 1958-1963.

doi:10.1109/TMAG.1985.1064031.

[26] R. Madugundo, G.C. Hadjipanayis, Anisotropic Mn-Al-(C) hot-deformed bulk magnets, J. Appl. Phys. 119 (2016) 013904. doi:10.1063/1.4939578. 
[27] Y. Sakamoto, A. Ibata, S. Kojima, T. Ohtani, New MnAlC permanent magnets exhibiting macroscopically-plane magnetic-anisotropy, IEEE Trans. Magn. 16 (1980) 1056-1058. doi:10.1109/TMAG.1980.1060672.

[28] T. Ohtani, N. Kato, S. Kojima, K. Kojima, Y. Sakamoto, I. Konno, M. Tsukahara, T. Kubo, Magnetic properties of Mn-Al-C permanent magnet alloys, IEEE Trans. Magn. 13 (1977) 1328-1330. doi:10.1109/TMAG.1977.1059574.

[29] J. Thielsch, F. Bittner, T.G. Woodcock, Magnetization reversal processes in hot-extruded $\tau$-MnAl-C, J. Magn. Magn. Mater. 426 (2017) 25-31. doi:10.1016/j.jmmm.2016.11.045.

[30] F.E. Pinkerton, D.J. Van Wingerden, Magnetization process in rapidly solidified neodymium-iron-boron permanent magnet materials, J. Appl. Phys. 60 (1986) 3685-3690. doi:10.1063/1.337576. 